\title{
Assessment of Post-Traumatic and Postoperative Inferior Alveolar Nerve Function in Mandibular Angle Fracture
}

Hafsa Maqbool ${ }^{1}$, Musarat Abro' ${ }^{2}$, Syed Ghazanfar Hassan ${ }^{3}$, Hira Yousuf ${ }^{4}$, Suneel Kumar Punjabi ${ }^{5}$ and Salman Shams ${ }^{6 *}$

${ }^{1}$ Resident, Oral and Maxillofacial Surgery Department, Faculty of Dentistry, Liaquat University of Medical and Health Sciences, Pakistan

${ }^{2}$ Senior Lecturer, Prosthodontics Department, Faculty of Dentistry, Dow University of Health Sciences Pakistan

${ }^{3}$ Professor, Oral and Maxillofacial Surgery Department, Faculty of Dentistry, Liaquat University of Medical and Health Sciences, Pakistan

${ }^{4}$ Resident, Oral and Maxillofacial Surgery Department, Faculty of Dentistry, Liaquat University of Medical and Health Sciences, Pakistan

${ }^{5}$ Associate Professor, Oral and Maxillofacial Surgery Department, Faculty of Dentistry, Liaquat University of Medical and Health Sciences, Pakistan

${ }^{6}$ Senior Lecturer, Oral and Maxillofacial Surgery Department, Faculty of Dentistry, Liaquat University of Medical and Health Sciences, Pakistan

\section{ABSTRACT}

Objective: To assess the inferior alveolar nerve function post-trauma (post-injury) and post-surgery (open reduction and internal fixation).

Study Design: Descriptive Cross-Sectional Study

Place and Duration of Study: The Department of Oral \& Maxillofacial Surgery, Institute of Dentistry, LUMHS, Jamshoro (From February 2018 - December 2018)

Methodology: Total 56 patients having fracture of angle of mandible were included. Inferior alveolar nerve function was assessed by Two-point discrimination method at post-injury (pre-operatively), and after mandibular fracture treatment with open reduction and internal fixation and at follow up visits i.e. at $1^{\text {st }}$ week, $4^{\text {th }}$ week, $8^{\text {th }}$ week, $12^{\text {th }}$ week and at $16^{\text {th }}$ week. Categorical variables were expressed as frequencies and percentage and for continuous variables, mean and standard deviation were measured.

Results: There were $67.8 \%$ male and $32.2 \%$ female patients. Of which $30.2 \%$ patients aged 21 to 30 years, $51.9 \%$ aged 31 to 40 years, and $17.9 \%$ aged 41 to 50 years. It was observed that $58.9 \%$ patients had right sided fracture and $41.1 \%$ patients had left sided fracture. Preoperatively inferior alveolar nerve assessment showed intact in all patients. Postoperatively at $16^{\text {th }}$ week $91.1 \%$ were positive at lip and $89.3 \%$ were positive at chin.

Conclusion: Fractures of angle of mandible play a major role in the neurosensory deficit of the Inferior Alveolar nerve. Fracture site was related to effects too. The IAN deficits do not affect by age and sex.

KEYWORDS: Inferior alveolar nerve function; Post-trauma; Open reduction and internal fixation

ABBREVIATIONS: ORIF: Open Reduction with Internal Fixation; IAN: Inferior Alveolar Nerve; OPD: Outpatient Department; OPG: Orthopantomogram

Quick Response Code:

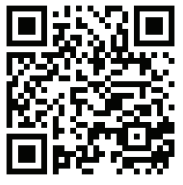

Address for correspondence: Salman Shams, BDS, MSc. Senior Lecturer, Department of Oral and Maxillofacial Surgery, Liaquat University of Medical \& Health Sciences, Pakistan

Received: August 01, $2020 \quad$ Published: August 10, 2020

How to cite this article: Hafsa M, Musarat A, Syed GH, Hira Y, Suneel KP, Salman S. Assessment of Post-Traumatic and Postoperative Inferior Alveolar Nerve Function in Mandibular Angle Fracture. 2020 - 2(4) OAJBS.ID.000205. DOI: 10.38125/OAJBS.000205 


\section{INTRODUCTION}

Fracture can be defined as "The breach and disturbance in the continuity of bone" [1]. Divine and exclusive anatomical position of mandible makes it most prominent and most fractured site among facial structures [2]. This vulnerability of mandible fracture can be due to the presence of weak mechanical components i.e. angle and condylar process with extent of $23.8 \%$ to $81.3 \%$ [3]. Etiology of fracture mandible varies with country and age, however major sources of trauma include motor-vehicle accidents, work-related distress, violation attack or sport related injuries [4].

Mandibular fractures may affect one's lifestyles and causes pain, mastication problems, malocclusion, may also cause TMJ problems [5]. The treatment options includes closed reduction and open reduction with internal fixation (ORIF) [5]. Many times, ORIF accompanies post-operative complications like inappropriate wound-healing and nerve disturbances however the most common complication encountered is mental nerve hypoesthesia whether transient (resolves later) or permanent [4].

Fractures of mandible located halfway to mental and mandibular foramen generally results in inferior alveolar nerve damage (I.A.N) [6]. Patient may experience pain, paraesthesia, dysaesthesia, hypoesthesia or anesthesia of chin, lower lip and gums [2]. The post-injury (after accident) hypoesthesia extent is up to $81 \%$, with intact pre-operative IAN function; there is postoperative hypoesthesia incidence at around $30 \%$ caused by surgical technique complication during ORIF [4]. There is well documented recovery of IAN has been published at around 33\% to $100 \%$ which advocates likely future of I.A.N recovery [4]. Circumstances which may affect I.A.N recovery include age, gender, fracture displacement, its site, type, treatment technique and the time elapsed between injury and its repair [7]. For classification of nerve injuries and lesions, Sir Herbert Seddon in 1943 proposed the three basic types of nerve injuries as neurapraxia, axonotmesis, and neurotmesis [8]. Injured sensory nerve can be diagnosed by static light touch method, brush method, two-point discrimination, the pin pressure method and by thermal testing methods [9].

Inferior alveolar nerve (I.A.N) is one of the most vital structures and its traumatic injury negatively affects the patient's quality of life and ability to translate functional meaningful behaviours and response. The aim of this research work is to objectively analyse the I.A.N nerve function for the establishment of accurate trauma management protocols before and after open reduction and internal fixation. Hence the study will be beneficial in favor for the management of Inferior alveolar nerve.

\section{MATERIAL AND METHODS}

This descriptive cross-sectional study comprising 56 patients was carried out at Oral \& Maxillofacial Surgery Department, Institute of Dentistry, Liaquat University of Medical and Health Sciences, Jamshoro. 2018.

Duration of Study: Six months from February 2018-December

\section{Inclusion Criteria}

a) Patients having fracture position wherever the stability of the IAN can be injured i.e. Fracture of Angle of mandible.

b) Patients with intact inferior alveolar nerve.

c) Patients above the age of 18 years. d) Patients of either gender.

e) Patient found fit for undergoing general anesthesia.

\section{Exclusion Criteria}
a) Close reduction and use of Trans-osseous wiring.
b) Patients having numbness of inferior alveolar nerve.
c) Patients having panfacial fractures.
d) Patients who are medically compromised.
e) Bilateral fractures of mandible.
f) Patients not ready to take part in the study.

\section{DATA COLLECTION PROCEDURE}

Patients fulfilling the inclusion criteria were enlisted for this study reported to Outpatient Department (OPD) or all the way through causality of Liaquat University of Medical \& Health Sciences Jamshoro/ Hyderabad. Pre-operative/Post-injury status was checked by clinical sensory method "Two-Point discrimination", patients with intact inferior alveolar nerve function were enrolled for this study. Proper history of patient included biodata, hospital registration number, presenting complaints and clinical features including signs and symptoms and location of mandibular fracture were documented on Proforma. Study was carried out after approval from Ethical Review Committee of university.

Diagnosis of mandibular fracture was made through clinical examination, Orthopantomogram (OPG) and P.A view of face. Inferior alveolar nerve function was assessed by clinical nerve testing method i.e. two-point discrimination method at post-injury (pre-operatively) and after mandibular fracture treatment with open reduction and internal fixation and at follow up visits i.e. at $1^{\text {st }}$ week, $4^{\text {th }}$ week, $8^{\text {th }}$ week, $12^{\text {th }}$ week and at $16^{\text {th }}$ week.

\section{PROCEDURE}

Two Point Discrimination: In this method patient's ability to discriminate between two points was measured with a sliding calliper. In this test, the two pointed, but not sharp, tips of the calliper were touched across the area of involvement (Lip and chin) simultaneously with light pressure while the patient's eyes were closed. The separation of the two points were gradually reduced from $20 \mathrm{~mm}$ at the chin and $10 \mathrm{~mm}$ at the lips to the moment where the patient can feel one point only. The minimum separation at which two points were reported recorded. Distances $2 \mathrm{~mm}$ greater than the preoperative values were considered abnormal (negative). All the findings were recorded on structured Proforma (Annexure 1) and were evaluated after the completion of follow-up period. The Data were assessed by statistical software package SPSS version 20.0 .

\section{RESULTS}

The study results showed that among total 56 patients, $67.8 \%$ were male and rest of the $32.2 \%$ were female, as presented in Table 1. $30.2 \%$ patients belonged to age group 21 to 30 years, $51.9 \%$ patients belonged to age group 31 to 40 years, and $17.9 \%$ patients were in age group 41 to 50 years, as presented in Table 2. As far as sides of fracture are concerned, it was observed that $58.9 \%$ patients had right sided fracture and $41.1 \%$ patients had left sided fracture. The results are also presented in Table 3. Preoperatively inferior alveolar nerve assessment showed intact in all patients. Postoperatively assessment according to lip and chin were evaluated. 
Table 1: Frequency distribution of gender $(n=56)$.

\begin{tabular}{|c|c|c|}
\hline & Frequency & (\%) \\
\hline Male & 38 & 67.8 \\
\hline Female & 18 & 32.2 \\
\hline TOTAL & 56 & \\
\hline
\end{tabular}

Table 2: Frequency distribution of age groups $(n=56)$.

\begin{tabular}{|c|c|c|}
\hline & Frequency & (\%) \\
\hline $21-30$ & 17 & 30.2 \\
\hline $31-40$ & 29 & 51.9 \\
\hline $41-50$ & 10 & 17.9 \\
\hline TOTAL & 56 & \\
\hline
\end{tabular}

Table 3: Frequency distribution of side of fracture $(n=56)$.

\begin{tabular}{|c|c|c|}
\hline & Frequency & (\%) \\
\hline Right Side Angel & 33 & 58.9 \\
\hline Left Side Angle & 23 & 41.1 \\
\hline TOTAL & 56 & \\
\hline
\end{tabular}

A comparison of positive response among lip and chin is presented in Figure 1. A comparison of negative response among lip and chin is presented in Figure 2.

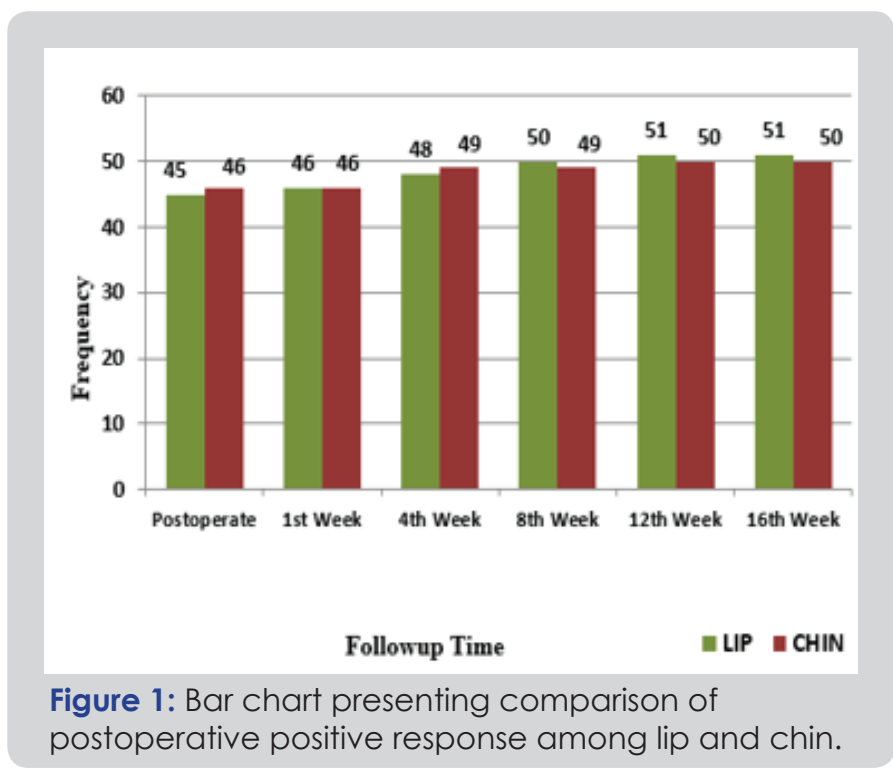

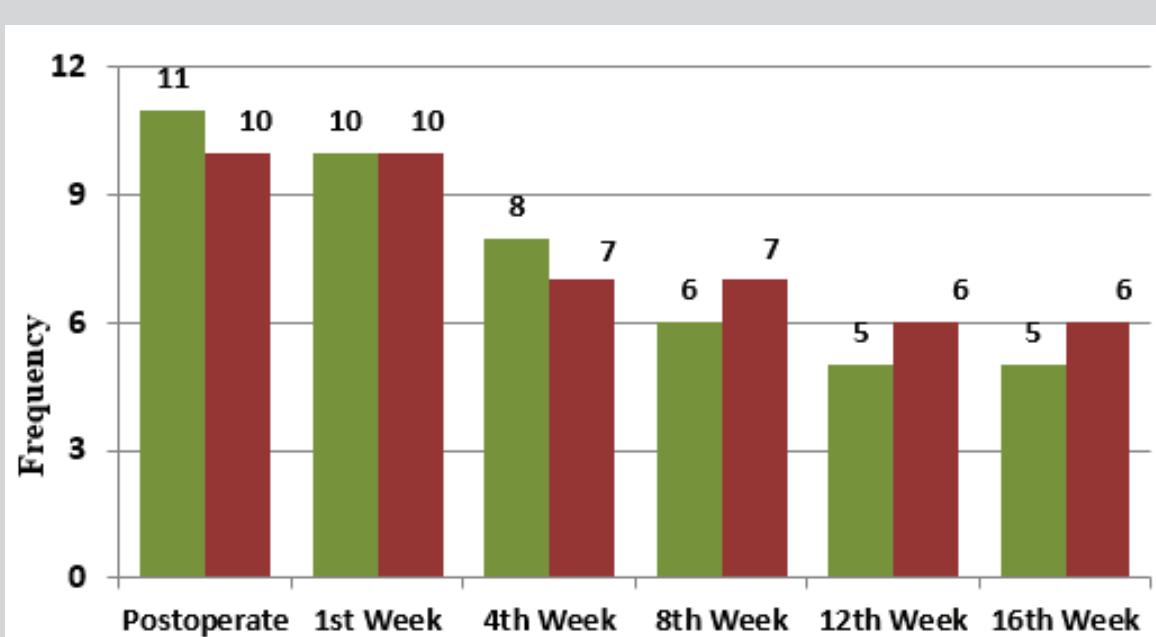

Followup Time

- LIP $\square$ CHIN

Figure 2: Bar chart presenting comparison of postoperative negative response among lip and chin.

\section{DISCUSSION}

The present study included the 2-point discrimination method for the assessment of IAN neurosensory function. A study from India had the objective of evaluating post-traumatic \& postoperative sensory instabilities of the IAN in mandibular fractures for the purpose of identifying the risk factors that are related to the deficit [10]. In their research, the mean age was 27yrs (vary from 16-40 years) with no substantial connotation found amid neurosensory consequence, gender or age. In the present research $30.2 \%$ patients belonged to age group 21 to 30 years, $51.9 \%$ patients belonged to age group 31 to 40 years and $17.9 \%$ patients belonged to age group 41 to 50 years. In an Indian study, Yadav et al. [10] reported that $86.7 \%$ of the patients had the presence of immediate post-traumatic sensory deficit. This study did not consider the neurosensory shortfalls in the post-traumatic period due to indirect injuries as the assessment was done of those direct injuries to the IAN that encompassed the fracture line. They also reported that the location of the fracture had no impression on the neurosensory deficit in the post-traumatic period and there was no correlation between the post-traumatic assessment score and the post-surgical neurosensory outcomes. The present study reported that $58.9 \%$ patients had right sided fracture and $41.1 \%$ patients had left sided fracture. Various studies have reported the finding of neurosensory deficit as an incidental one or if they have been complained about by the patients themselves [11,12]. Also, it has been noted that the numerous studies included mandibular fractures that did not encompass the mandibular canal [11-13] or did not involve cases where the IAN was directly injured [14-15]. Both these scenarios would have led to a considerably reduced frequency of neurosensory deficits in patients with mandibular fractures. 
Iizuka and Lindquist reported the presence of persistent neurosensory deficits in $46.6 \%$ of the patients over a mean followup period of 15.9 months. However, the reason for the reporting of this higher percentage could be due to the fact that Iizuka and Lindquist included displaced fractures $(76 \%)$ as well as edentulous fractures $(30 \%)$ in the study. All the patients were treated with ORIF [16].

Yadav et al. [10] reported the presence of post-traumatic neurosensory deficit in $23.3 \%$ of their patients after a follow-up of 12 months while in our study the neurosensory deficit after 4 months of follow-up was reported to be $91.1 \%$ on lip and $89.3 \%$ on chin. Queral-Godoy et al. [17] puts forth the hypothesis that the faster rate of healing of IAN and much favorable outcomes observed in cases of IAN injury is due to the fact that the nerve is protected within the mandibular canal extending from the mental foramen to the mandibular foramen which points to the findings that the location of the fracture as well as the displacement due to the fracture have a key role in the occurrence as well as worsening of the IAN neurosensory deficit in the post-traumatic and postoperative periods.

Yadav et al. [10] reported non-significant relationship amid the post-traumatic neuro-sensory mark \& ORIF procedure with the deterioration in the IAN neurosensory score. It has been observed that the presence of displaced fractures resulted in increased incidence of neurosensory deficit and was almost followed by a longer recovery period. The cause behind these findings could be the direct trauma to the IAN as a result of the displacement or the trauma to the nerve could occur during the surgical procedure [18].

Yadav et al. [10] reported that as all their patients underwent ORIF procedure which included mini-plates, single-cortical screws \& anatomical settlement, thus the hazard of a much worse IAN neurosensory deficit mark was considerably less in the postoperative period. In our study, the same procedure i.e. ORIF was used and thus the incidence of a much detoriated neurosensory deficit score in the post-operative period was highly unlikely. Stacey et al. [19] also have reported a higher efficacy of non-compressive miniplate fixation of mandibular fractures owed to combined effect of lower rate of morbidity as well as complications in the postoperative period. The finding of no worsening of neurosensory deficit in the post-operative period as reported by Yadav et al. [10] matches well with our study and similar findings were also similarly published by Schultze-Mosgau et al. [18].

\section{CONCLUSION}

Fractures of angle of mandible play a major role in the neurosensory deficit of the Inferior Alveolar nerve. Fracture position was related with consequences too. IAN deficits don't affect by gender and age.

\section{CONFLICT OF INTEREST (FUNDING SOURCE)}

All the Examination instruments were used in this study were readily available are provided by Department of Oral and Maxillofacial Surgery, Liaquat University Hospital, Jamshoro/ Hyderabad. Hence there was no funding or incentive associated in this regard.

\section{REFERENCES}

1. Natu SS, Pradhan H, Gupta H, Alam S, Gupta S, et al. (2012) An epidemiological study on pattern and incidence of mandibular fractures. Plast Surg Int 2012: 834364.
2. Song Q Li S, Patil PM (2014) Inferior alveolar and mental nerve injuries associated with open reduction and internal fixation of mandibular fractures: A Seven Year retrospective study. J Craniomaxillofac Surg 42(7): 1378-1381.

3. Zhou H, Lv K, Yang R, Li Z (2016) Mechanics in the production of mandibular fractures: A clinical, retrospective case-control study. PLoS One 11(2): e0149553.

4. Schenkel JS, Jacobsen C, Rostetter C, Grätz KW, Rücker M, et al. (2016) Inferior alveolar nerve function after open reduction and internal fixation of mandibular fractures. J Craniomaxillofac Surg 44(6): 743-748.

5. Boffano P, Kommers SC, Roccia F, Forouzanfar T (2015) Mandibular trauma treatment: A comparison of two protocols. Med Oral Patol Oral Cir Bucal 20(2): e218-e223.

6. Boffano P, Roccia F, Gallesio C, Karagozoglu K, Forouzanfar T (2014) Inferior alveolar nerve injuries associated with mandibular fractures at risk: a two-center retrospective study. Craniomaxillofac Trauma Reconstr 7(4): 280-283.

7. Rehman A, Noreen R, Ahmad T, Din Q (2014) Post traumatic inferior alveolar nerve impairment and recovery pattern in mandibular fractures. Journal of Khyber College of Dentistry (JKCD) 4(2): 29-33.

8. Chhabra A, Ahlawat S, Belzberg A, Andreseik G (2014) Peripheral nerve injury grading simplified on MR neurography: As referenced to Seddon and Sunderland classifications. Indian J Radiol Imaging 24(3): 217-224.

9. Kim YK, Yun PY, Kim JH, Lee JY, Lee W (2015) The quantitative sensory testing is an efficient objective method for assessment of nerve injury. Maxillofac Plas and Reconstru Surg 37(1): 13.

10. Yadav S, Mittal H, Malik S, Dhupar V, Sachdeva A, et al. (2016) Posttraumatic and postoperative neurosensory deficits of the inferior alveolar nerve in mandibular fracture: a prospective study. J Kor Ass Oral Maxillo Surg 42(5): 259-264.

11. Tu HK, Tenhulzen D (1985) Compression osteosynthesis of mandibular fractures: a retrospective study. J Oral Maxillofac Surg 43: 585-589.

12. Niederdellmann H, Shetty V (1987) Solitary lag screw osteosynthesis in the treatment of fractures of the angle of the mandible: a retrospective study. Plast Reconstr Surg 80: 68-74.

13. Ardary WC (1989) Prospective clinical evaluation of the use of compression plates and screws in the management of mandible fractures. J Oral Maxillofac Surg 47: 1150-1153.

14. Luhr HG, Reidick T, Merten HA (1996) Results of treatment of fractures of the atrophic edentulous mandible by compression plating: a retrospective evaluation of 84 consecutive cases. J Oral Maxillofac Surg 54: $250-254$.

15. Kuriakose MA, Fardy M, Sirikumara M, Patton DW, Sugar AW (1996) A comparative review of 266 mandibular fractures with internal fixation using rigid (AO/ASIF) plates or mini plates. Br J Oral Maxillofac Surg 34: 315-321.

16. Iizuka T, Lindquist C (1991) Sensory disturbances associated with rigid internal fixation of mandibular fractures. J Oral Maxillofac Surg 49: 1264.

17. Queral-Godoy E, Valmaseda-Castellón E, Berini-Aytés L, Gay-Escoda C (2005) Incidence and evolution of inferior alveolar nerve lesions following lower third molar extraction. Oral Surg Oral Med Oral Pathol Oral Radiol Endod 99: 259-264.

18. Schultze-Mosgau S, Erbe M, Rudolph D, Ott R, Neukam FW (1999) Prospective study on post-traumatic and postoperative sensory disturbances of the inferior alveolar nerve and infraorbital nerve in mandibular and midfacial fractures. J Craniomaxillofac Surg 27(2): 8693.

19. Stacey DH, Doyle JF, Mount DL, Snyder MC, Gutowski KA (2006) Management of mandible fractures. Plast Reconstr Surg 117: 48e-60e. 